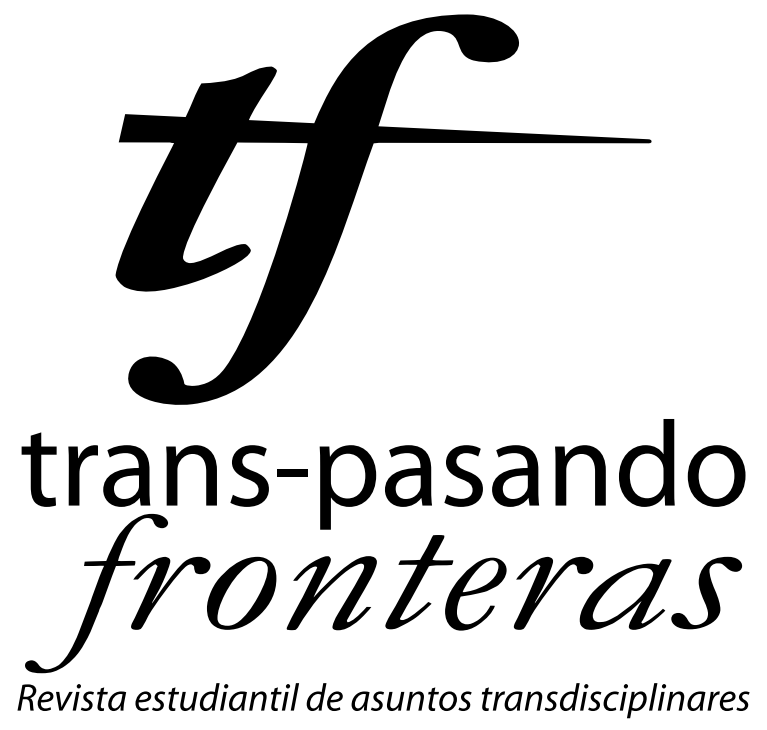

Una publicación de

Estudios

Interdisciplinarios

Jurídicos, Sociales

000 y Humanistas

ICESS

FACULTAD DE

DERECHO Y CIENCIAS

SOCIALES

然 UNIVERSIDAD 


\title{
La dimensión de lo actitudinal en las trayectorias de dos políticos profesionales colombianos
}

\author{
Rafael Silva Vega* \\ (rsilva1@icesi.edu.co)
}

Artículo de reflexión recibido el 22/10/2013 y aprobado el 23/11/2013.

\begin{abstract}
Como citar este artículo:
SILVA VEGA, Rafael (2013). "La dimensión de lo actitudinal en las trayectorias de dos políticos profesionales colombianos”. En: Trans-pasando Fronteras, Núm. 4, pp. 173-207. Cali, Colombia: Centro de Estudios Interdisciplinarios, Jurídicos, Sociales y Humanistas (CIES), Facultad de Derecho y Ciencia Sociales, Universidad Icesi.
\end{abstract}

\begin{abstract}
Resumen
Este trabajo se inscribe en un ejercicio de investigación sobre "políticos profesionales" en América Latina. Está dedicado al análisis de la dimensión de lo actitudinal en las trayectorias de dos políticos colombianos, Antanas Mockus Šivickas y Gustavo Petro. A partir de un análisis cualitativo, se indaga el ámbito de lo actitudinal de estos dos políticos en términos de la consolidación y la valoración de la calidad de la democracia; asimismo, se estudian las semejanzas y las diferencias entre ellos, con el fin de señalar sus aportes a la consolidación de la democracia en Colombia.
\end{abstract}

\section{Palabras claves}

Políticos profesionales, Dimensión de lo actitudinal, Democracia, Colombia.

* Licenciado en Filosofía de la Universidad del Valle, con Maestría en Filosofía Política y Ética en la misma universidad. Actualmente se encuentra realizando sus estudios doctorales en Ciencias Sociales con Especialización en Estudios Políticos en la Facultad Latinoamericana de Ciencias Sociales (FLACSO), Ecuador. Es Profesor Asistente de la Facultad de Derecho y Ciencias Sociales de la Universidad Icesi y miembro del grupo de investigación "Nexos". 


\section{Introducción}

Tal como sostienen García y Mateos (2006), la perspectiva conceptual de la política como sistema propuso a la Ciencia Política una nueva unidad de análisis, es decir, la conducta humana en sus expresiones políticas. De acuerdo con este enfoque teórico, los individuos son quienes protagonizan los procesos de gobierno. Sin embargo, al hablar aquí de individuos se hace referencia a "actores institucionalizados" relevantes (García y Mateos, 2006: 3) de los cuales, también, su acción política está estrechamente ligada a sus percepciones, ideales, creencias, valores, actitudes y orientaciones políticas desde la que estos agentes "construyen su visión de la política y su posición política como representantes dentro de la misma” (García y Mateos, 2006: 3).

Desde este punto de vista, los políticos como actores institucionalizados, es decir como políticos profesionales, que al decir de Weber viven "para la política" y "de la política" (Weber, 1972: 95), no han dejado de ser uno de los protagonistas principales y básicos de la vida política en las democracias contemporáneas. Pero además de esto, convendría agregar, para argumentar a favor de este enfoque de análisis, que la importancia y la urgencia de seguir estudiando al político profesional, y el modo como éste se relaciona con su mundo político, está dada por la naturaleza de los cambios de la realidad política, social y económica del mundo actual y, por ende, por la propia manera como los cambios de estos entramados institucionales, y del sistema político mismo, han modificado la propia naturaleza del político, de su actividad, de su rol y de sus propios fines e intereses. Entonces, ¿por qué no seguirlos estudiando? Aún más cuando existen regiones en el mundo donde estos actores no han sido estudiados de forma sistemática y a profundidad como lo revelan los trabajos de investigadores que han asumido esta labor para la región latinoamericana.

Alcántara, por ejemplo, sostiene que una de las razones que lo han llevado a centrar sus investigaciones sobre el político profesional en América Latina ha sido "la ausencia de estudios sobre la profesionalización de la política en el área" (Alcántara, 2012: 237). De la misma forma, García y Mateos han argumentado que sus trabajos sobre las élites políticas en América Latina tienen la intención de llenar el vacío que hay en esta parte del mundo en el análisis de este objeto de investigación (García y Mateos, 2006: 4). Y, como han mostrado los trabajos investigativos del 
PELA, ${ }^{1}$ resulta muy significativo poder estudiar a los políticos profesionales latinoamericanos, en el contexto del reforzamiento y el fortalecimiento que empezaron a vivir las instituciones democráticas latinoamericanas a partir de la década de 1980, para examinar sus percepciones, ideales, creencias, valores, actitudes y orientaciones políticas en relación con la consolidación y la valoración de la calidad de la democracia en esta región del mundo.

En este sentido, este trabajo está dedicado a analizar la dimensión de lo actitudinal en las trayectorias de dos políticos profesionales colombianos, Antanas Mockus Šivickas y Gustavo Petro. La primera parte está dedicada a poner en claro los aspectos teóricos y metodológicos desde los cuales se emprende el análisis. La segunda parte es una breve caracterización histórica de la democracia colombiana con el fin de poner el contexto en donde actúan los dos políticos a estudiar. La tercera y cuarta parte se analiza la dimensión de lo actitudinal en ambos políticos. Y en la quinta parte se elaboran las conclusiones desde el examen de las semejanzas y diferencias en la dimensión de lo actitudinal en Mockus y Petro.

\section{Aspectos teóricos y metodológicos}

\section{Planteamiento del problema}

En este orden de ideas, el presente trabajo se inscribe en el ejercicio de investigación sobre "políticos profesionales" en América Latina. Pero, más específicamente, en el contexto de las élites políticas de Colombia, una clase política de la cual se sabe poco en términos académicos y que, por lo general, casi no es frecuentada como objeto de estudio por los investigadores sociales; una explicación plausible para este hecho recae tal vez en su complejidad o en el contexto enrarecido en el que ella vive y actúa, específicamente se hace referencia a fenómenos como la violencia, la corrupción, el narcotráfico y la ilegalidad, entre otros. Así, este ejercicio investigativo va a consistir en indagar las percepciones, ideales, creencias, valores, actitudes y orientaciones políticas en las trayectorias de dos políticos profesionales colombianos -Antanas Mockus Šivickas y Gustavo Petro-, en el contexto de lo que García y Mateos han llamado la consolidación y la valoración de la calidad de la democracia (García y Mateos, 2006).

1 Grupo de investigación dirigido por Manuel Alcántara Sáez y vinculado al Instituto Interuniversitario de Iberoamérica y al Área de Ciencia Política y de la Administración de la Universidad de Salamanca. 
En términos mucho más concretos, la pregunta central que se propone indagar en este trabajo es: ¿cuáles son las percepciones, ideales, creencias, valores, actitudes y orientaciones políticas que, en términos de la "consolidación y la valoración de la calidad de la democracia”, tienen Antanas Mockus Šivickas y Gustavo Petro en sus trayectorias políticas?

\section{Pertinencia del análisis}

En Bowling Alone: The Collapse and Revival of American Community (2000) Robert Putnam sostiene, en líneas generales, que a partir de la década de los sesenta del pasado siglo en los Estados Unidos se ha asistido a un declive del civismo y de la vida política con consecuencias lamentables para la sociedad norteamericana. Este colapso del sentido social y político de la comunidad estadounidense, que ha llevado a un acrecentamiento del individualismo, o sea, a la reclusión de la ciudadanía a la esfera de la vida privada con el consecuente abandono de la vida pública o del compromiso cívico, es decir, de la confianza social y de la conciencia cívica de los ciudadanos (Putnam, 2000: 13), medido por el autor en términos del capital social (Putnam, 2000). Según Putnam:

Mientras el capital fisico se refiere a objetos fisicos, y el humano a propiedades de las personas, el capital social guarda relación con los vínculos entre individuos las redes sociales y las normas de reciprocidad y confianza derivadas de ellas. En este sentido, el capital social está estrechamente relacionado con lo que algunos han llamado "virtud cívica". La diferencia reside en que el capital social atiende al hecho de que la virtud civica posee su mayor fuerza cuando está enmarcada en una red densa de relaciones sociales recíprocas (Putnam, 2000: 14).

En este sentido, para este teórico e investigador norteamericano, la vitalidad y grandeza de una comunidad política depende de la fortaleza de los vínculos sociales entre los individuos, de su virtud cívica o, lo que es lo mismo, de su "compromiso cívico", es decir, de su confianza, respeto, apoyo, solidaridad, sentido de pertenencia y defensa de las leyes, instituciones y, en general, del bien común de la sociedad política. Obviamente, Putnam no desconoce que el "capital social" puede tener un lado negativo, es decir, que ciertos vínculos sociales y redes de apoyo pueden dirigirse “hacia objetivos malintencionados y antisociales” (Putnam, 2000: 19). Lo que, según 
él, le facilitó a "Timothy Mcveigh volar con una bomba el edificio federal Alfred $P$. Murrah de la ciudad de Oklahoma" (Putnam, 2000: 19). Esta observación, de paso, si tomamos en serio la asociación que ha hecho Putnam entre el capital social y la virtud cívica, también nos ha de prevenir acerca de que esta última puede albergar un lado oscuro. Por tal razón, como lo señala el propio Putnam es sus investigaciones, lo importante es enfocarse en los aspectos positivos del capital social o de la virtud cívica que son los que posibiltan el sentido social y político en una comunidad democrática. Es decir, la generación y el fortalecimiento de vínculos sociales que sean propicios para la consolidación de una forma de vida democrática que propicie, defienda y garantice las libertades y derechos de las personas, la justicia, la equidad, la reciprocidad y, en términos generales, el "respeto" (Sennett, 2003).

De todas maneras, se debe advertir que la consolidación de la vida democrática en una sociedad política no depende única y exclusivamente de la virtud cívica. Existen otros elementos que son factores determinantes para que esto ocurra como, por ejemplo, las instituciones políticas. Machiavelli en I Discorsi había sostenido que "li buoni esempli nascano dalla buona educazione, la buona educazione, dalle buone leggi” (Machiavelli, 1971: 95)², para sugerir que la virtud sola no basta sino está acompañada de buenas instituciones y, a la inversa, las buenas instituciones no son suficientes sino están las buenas costumbres ciudadanas. En este sentido, Alcántara, desde sus investigaciones sobre la élite política, ha reconocido que las instituciones bajo las que se mueven los ciudadanos y los políticos tiene "una gran capacidad para modelar el comportamiento" de estos (Alcántara, 2012: 29). Esto mismo es evidenciado en Rohrschneider en su interesante trabajo sobre la influencia de las instituciones en los valores de las élites políticas de Alemania antes y después de la unificación (Rohrschneider, 1994).

Ahora bien, esta especie de reciprocidad o, más bien, de mutua dependencia entre lo institucional y las prácticas de los ciudadanos -políticos profesionales o no-, que pueden ser capaces de sostener desde sus "buenas costumbres" la estructura institucional o, por el contrario, si no son adecuadas hacerla inviable, nos devela otro elemento 
que es de gran importancia en la consolidación del sentido social y político de la democracia en cualquier sociedad: la dimensión de lo actitudinal. En efecto, además de las instituciones y de las prácticas, la disposición de los ciudadanos hacia el tipo o la forma de gobierno de su comunidad política es un factor que resulta decisivo para saber si esa forma de vida política tiene posibilidades se consolidarse o no. A este respecto, García y Mateos han argumentado que:

\begin{abstract}
Junto a la dimensión institucional y la de comportamiento (behavioral), la dimensión actitudinal se instituye como una de las dimensiones capitales de la consolidación de los regímenes democráticos. No se puede hablar de consolidación democrática si la opinión pública, en general, y la clase política en particular, no sostiene la creencia de que los procedimientos democráticos son la mejor forma de gobernar la vida colectiva de las sociedades (García y Mateos, 2006: 9).
\end{abstract}

Por eso la dimensión actitudinal es de un valor sin igual en lo que tiene que ver con los análisis sobre la consolidación de la democracia. Pues son las percepciones, ideales, creencias, valores, actitudes y orientaciones políticas de los ciudadanos las que, a la larga, aportan legitimidad al régimen político. Si los ciudadanos creen en las instituciones y en las reglas de juego de la democracia, muy seguramente esa forma de vida democrática echará raíces y se hará perdurable. Por eso es importante indagar la dimensión de lo actitudinal entre los ciudadanos y con mayor razón, se hace indispensable examinarla en aquellos ciudadanos que están investidos de autoridad política y que, por eso, ostentan cargos, funciones y dignidades públicas. Es decir, aquellos ciudadanos que detentan el poder o están alrededor de los poderosos para aconsejarlos (Alcántara, 2012: 31). Pues son estos, los políticos profesionales, quienes, de una u otra forma, por su papel de líderes de la comunidad política (Blondel y Thiébaut, 2010), terminan convirtiéndose en el referente actitudinal y del obrar político, ético y social del resto o, mejor, de la gran mayoría de los ciudadanos en una sociedad. Ellos pueden llegar a ser, como dice Alcántara recordando a Plutarco, "un buen ejemplo moral para inspirar la confianza y autoridad ante el pueblo" (Alcántara, 2012: 31). Pero, como afirma Putnam sobre los efectos negativos del capital social, pueden también llegar a ser lo contrario.

Con base en estas últimas ideas, en este trabajo se parte de la tesis de que el estudio 
de la dimensión de lo actitudinal resulta mucho más sugerente en sistemas políticos en los cuales, pese a haber entrado en la ruta de la democracia y de sus reglas de juego en términos formales e institucionales, siguen persistiendo agudos problemas sociales como la desigualdad social, la discriminación, la violencia social y política, el conflicto, la corrupción y hasta el narcotráfico. Un buen ejemplo de este tipo de sistema político y social es un país como Colombia. Ubicado en la zona noroccidental de América del Sur, este país ha hecho grandes esfuerzos por entrar en la seda de la democracia desde finales del siglo XX y principios del XXI, en términos del diseño de sus instituciones políticas, jurídicas y sociales, prueba de ello es su Constitución política de 1991 con la cual este país e importantes sectores de su sociedad se esforzaron por ponerse al día, en términos de los estándares internacionales, con las exigencias de los mandatos democráticos del orbe occidental. No obstante estos importantes logros institucionales, Colombia sigue, al día de hoy, atravesada por agudos conflictos y problemas sociales como los antes señalados. Con el agravante de que no son los ciudadanos de a pie los únicos que se han visto afectados por estos fenómenos, o los únicos que han sido protagonistas y actores centrales de ellos. Pues, en las últimas décadas, los principales actores y propiciadores de estos fenómenos han sido los politicos profesionales de este país.

Llama la atención que en Colombia concejales, diputados, gobernadores, congresistas y hasta presidentes de la república se han visto involucrados, como protagonistas centrales y segundarios, en problemas de corrupción, narcotráfico, paramilitarismo, masacres, asesinatos y desplazamiento forzado de las poblaciones campesinas y grupos sociales minoritarios como indígenas y afrocolombianos. Para citar sólo un caso, de miles que están documentados en periódicos, revistas de opinión, archivos judiciales y libros e informes de investigación académica, basta con consultar la noticia del 15 de mayo de 2013 de un importante diario nacional colombiano sobre la condena a 30 años de prisión de quien fuera ex-presidente de la Cámara de Representantes de Colombia, César Pérez García, por su responsabilidad en la tristemente célebre masacre de Segovia. ${ }^{3}$

Este solo caso, de innumerables e igual o peor de atroces, nos tiene que llevar, inevitablemente, a cuestionarnos por la dimensión actitudinal de este tipo de político profesio-

3 Consultado desde: http:/www.elespectador.com/noticias/judicial/articulo-422140-condenan-30-anos-deprision-cesar-perez-garcia-masacre-de-segovi 
nal colombiano que incurre, sin ningún tipo de consideración o reato moral, en crímenes de lesa humanidad con tal de sacar adelante sus fines e intereses políticos. Como también de aquellos que, en la Colombia de hoy, no comparten los medios de los que se valen los políticos profesionales que han entrado en el camino de la criminalidad para realizar sus objetivos políticos y le apuestan, más bien, a hacer política desde las reglas de la democracias y de la Constitución política de 1991, es decir, desde la legalidad.

Un buen ejemplo de este tipo de político profesional que opera en y desde la legalidad es el de Antanas Mockus Šivickas y Gustavo Petro. El primero de ellos dio el salto a la política profesional desde la academia, mundo desde el cual tenía posturas críticas sobre la política y la democracia colombiana. El segundo hizo parte, en el pasado, del Movimiento 19 de abril (abreviado con el numerónimo M-19 o simplemente el eme), un grupo guerrillero que nació en la década de 1970 como consecuencia de un supuesto fraude electoral en las elecciones para presidente del 19 de abril de 1970. Después de la Asamblea Nacional Constituyente de 1991, que dio como origen la Constitución de 1991, Petro inicio su carrera como político profesional hasta el día de hoy.

Desde dos orillas distintas Mockus y Petro confluyeron, en el contexto institucional propiciado por la Constitución del 1991, en el ejercicio de la política profesional primero como líderes políticos que, para usar la conceptualización de Blondel y Thiébaut, en relación con los ciudadanos tenían notoriedad, popularidad y carisma (Blondel y Thiébaut, 2010: 15-20). ${ }^{4} \mathrm{Y}$, segundo, como políticos profesionales que empezaron a ocupar importantes cargos públicos en los poderes ejecutivo y legislativo del país y que desde sus carreras políticas han aportado, no sólo en términos de su ámbito actitudinal sino, además, desde sus obras políticas concretas, a la consolidación de la democracia colombiana. Razón por la cual resulta sumamente pertinente examinar sus trayectorias políticas para develar con mayor claridad cuáles han sido las percepciones, ideales, creencias, valores, actitudes y orientaciones desde las que han hecho política.

4 De acuerdo con Blondel y Thiébaut la reacción de los ciudadanos hacia los líderes personalizados se expresa en: a) notoriedad (se basa casi exclusivamente en la capacidad del ciudadano para "reconocer" un líder determinado); b) popularidad (es algo más fuerte, ya que indica que un líder dado disfruta, no sólo de reconocimiento, sino un grado de apoyo); c) "carisma" (se refiere al vínculo más poderoso entre el ciudadano y líder) (Blondel y Thiébaut, $2010: 15-20)$. 


\section{Enfoque teórico}

Este trabajo se inscribe teórica y conceptualmente en los desarrollos de las investigaciones de Robert Putnam, explícitamente en Bowling Alone: The Collapse and Revival of American Community (2002). Un trabajo de enormes dimensiones dedicado al análisis del colapso y el resurgimiento de la comunidad norteamericana desde la óptica de la pérdida de los vínculos sociales y de las normas de reciprocidad y confianza, derivadas de esos vínculos. Una investigación que propone como concepto central del análisis es el de capital social como actualización de la antigua y clásica noción de la virtud cívica usada de forma recurrente por los humanistas y filósofos políticos de la antigüedad clásica greco-romana y, luego, renacentista. En esta lógica, la propuesta investigativa de Putnam nos permite develar, en términos de una teoría de la ciudadanía y del ciudadano, el ámbito de los vínculos sociales como cemento de la vida comunitaria de cualquier sociedad como, también, la importancia que tienen para el fortalecimiento de la vida política en común el conjunto de percepciones, ideales, creencias, valores, actitudes y orientaciones políticas de los ciudadanos en relación con las instituciones y los políticos que los gobiernan.

En línea teórica de continuidad con los desarrollos de Putnam, se echa mano también aquí de las investigaciones realizadas por el PELA, especialmente de El Proyecto elites parlamentarias latinoamericanas: continuidades y cambios (1994-2005) de Fátima García Díez y Araceli Mateos Díaz (García y Mateos, 2006). Ya que el enfoque de investigación de los trabajos del PELA explora al ámbito de lo actitudinal -retomando las contribuciones de Putnam- pero centrado en "actores políticos institucionalizados", es decir, en políticos profesionales (García y Mateos, 2006: 3). Este cruce teórico entre los trabajos de Putnam y el PELA resulta muy apropiado para este trabajo que, si bien está centrado en la dimensión de lo actitudinal en dos políticos colombianos, parte en términos teóricos y conceptuales del presupuesto de que aunque los "políticos profesionales", por más que estén investidos de autoridad y de poder, no dejan de ser ciudadanos. Y, por tal razón, la dimensión de lo actitudinal en ellos adquiere una relevancia descomunal en la medida en que ellos son y (re)significan las prácticas y los valores de la ciudadanía en una democracia. Es decir, ellos como figuras de autoridad son el referente ético del resto de la ciudadanía por lo tanto sus 
prácticas políticas y disposiciones hacía las leyes e instituciones pueden consolidar o tirar por el abismo a la democracia.

\section{Metodología y objetivos}

La metodología con la que se realizó este trabajo consiste en el levantamiento de datos cualitativos que nos ayuden a esclarecer el ámbito de lo actitudinal en las trayectorias políticas de Antanas Mockus Šivickas y Gustavo Petro en términos de la consolidación y la valoración de la calidad de la democracia en Colombia. La revisión documental se llevó a cabo durante 15 días en la hemeroteca de la Biblioteca Mario Carvajal de la Universidad del Valle, en Cali, Colombia. Y tuvo como propósito rastrear las entrevistas y declaraciones de los dos actores políticos aquí propuestos, consignadas en tres fuentes seleccionadas previamente, el periódico El Espectador y la revista Semana, en un periodo delimitado que va del año 2008 al año 2012 -un lustro-. La otra fuente es la revista Cambio, en un periodo que va del año 2008 al año 2009. Este trabajo de levantamiento de la información fijó la mirada en un conjunto de ejes y variables-indicadores de análisis que el lector podrá encontrar de forma pormenorizada en la Tabla 5 de los Anexos de este trabajo.

Así, el objetivo general de este trabajo consiste, en términos concretos, en develar las percepciones, ideales, creencias, valores, actitudes y orientaciones políticas de Antanas Mockus Šivickas y Gustavo Petro en términos de la valoración y la consolidación de la democracia en Colombia. Y sus objetivos específicos son:

1. Contrastar las dimensiones de lo actitudinal en las trayectorias políticas de Antanas Mockus Šivickas y Gustavo Petro para ver que semejanzas y diferencias nos aportan.

2. Evaluar los aportes que, desde la dimensión de lo actitudinal, han hecho Antanas Mockus Šivickas y Gustavo Petro a la consolidación de la democracia en Colombia en el curso de sus trayectorias como políticos profesionales.

\section{Breve caracterización histórica de la democracia colombiana}

La democracia colombiana se ha caracterizado en el transcurrir de su historia por gozar de una aparente estabilidad institucional, combinada con los más profundos problemas sociales, políticos y económicos de entre los países de América Latina. Desde mediados 
del siglo XIX a inicios del XX, el país estuvo convulsionado por cuatro guerras civiles: 1876-77, 1885-86, 1895 y 1899-1902. Estas guerras, según Marco Palacios, "pusieron al descubierto la confrontación entre las elites acerca de cómo deberían ser las relaciones del tambaleante Estado nacional con el individuo, la Iglesia y las provincias" (Palacios, 2001: 15). En el intermedio de este periodo de guerras entre liberales y conservadores se fragua la Constitución política de 1886, de manos de Rafael Núñez y Miguel Antonio Caro. Una Constitución que fue producto no de un proceso democrático sino de una inestable alianza entre los bandos opositores y que, al final, termino siendo conservadora pues era "centralista, confesional y presidencialista" (Palacios, 2001: 15). Esta Constitución le dio milagrosamente unidad institucional al país, más no social, por 105 años. Asumió como oficial a la religión Católica, dividió el poder en tres ramas, estableció el periodo presidencial por seis años, creó los departamentos como unidades administrativas regionales y condujo al país por la senda de un conservadurismo duro que limitó fuertemente ciertas libertades individuales, en el plano ético, como la libertad de conciencia religiosa, entre otras (Melo, 1989).

Durante los 105 años que esta Constitución rigió a los colombianos, el país fue sacudido por la desigualdad social, la pobreza, luchas por los derechos civiles y políticos de la ciudadanía y el agudo conflicto entre liberales y conservadores que fue a parar, por un lado, a la época de La Violencia que, de acuerdo con Palacios, se dio en cuatro fases:

\footnotetext{
1) La del sectarismo tradicionalista, 1945-49. 2) La que abre la abstención liberal a fines de 1949 y cierra el gobierno militar en el segundo semestre de 1953. 3) La de los pájaros, de 1954 a 1958. Y finalmente, 4) la residual que, de la caída de Rojas a 1964, presenta un cuadro de descomposición, gamonalismo armado e intentos de reinserción de las bandas a la vida civil (Palacios, 2001: 189).
}

Por otro lado, al autoritarismo político que se fue consolidando en el país con el fuerte sistema presidencialista y con la instauración de un "estado de sitio permanente" (Palacios, 2001: 189) como instrumento para controlar cualquier forma de "desorden social". Y, al llamado Frente nacional, un acuerdo entre liberales y conservadores (1958 a 1974) que, con el propósito de ponerle coto a la violencia bipartidista y cerrarles el paso a otras opciones políticas que deseaban disputar el poder en términos de las reglas de la 
democracia, llevo a las elites bipartidistas a alternarse el poder por casi dieciséis años. Alianza que, en el fondo, fue un golpe mortal a la democracia en términos de la competencia política y del derecho a la contradicción política. De acuerdo con Chernick, con el Frente nacional "los remanentes de la competencia política se limitaron a las facciones rivales dentro de los partidos tradicionales: No obstante estas facciones no podían disputarse la presidencia. Por otro lado los partidos minoritarios distintos de los tradicionales quedaron completamente excluidos" (Chernick, 1989: 285). Pero, como expresión de su propia naturaleza, el Frente nacional, como afirma Palacios, "acentuó los principios de represión de las disidencias políticas, de control y cooptación de los sectores populares y de las clases medias emergentes, mediante la aplicación de redes de patronazgo y clientelismo" (Palacios, 2001: 239). Y, si bien logró poner fin a las guerrillas liberales y a la violencia bipartidista, vio emerger en su seno, a partir de 1964, grupos guerrilleros de izquierda como las Fuerzas Armadas Revolucionarias de Colombia (FARC, 1964). El Ejército de Liberación Nacional (ELN, 1965). El Ejército Popular de Liberación (EPL, 1967). El Movimiento 19 de abril (M-19, 1974). Y, el Movimiento Indigenista Quintín Lame (MAQL, 1984). Y si bien el desmonte gradual del Frente nacional, a partir de 1974, fue trayendo cierto grado de apertura democrática (Chernick, 1989: 316-320), el auge de los nuevos movimientos guerrilleros, aunado al fenómeno del narcotráfico, el paramilitarismo, la desigualdad social, la corrupción, el clientelismo y la pobreza fueron produciendo en Colombia lo que Eduardo Pizarro Leongómez ha denominado "una democracia asediada" (Pizarro, 2004).

Es, justamente, en medio de estas dolorosas y trágicas circunstancias -mediadas por procesos de paz, algunos fallidos y otros exitosos, con algunos grupos guerrilleros- que a inicios de la década de 1990 en el país, diversos sectores sociales, políticos y un renovado movimiento estudiantil hicieron un gran esfuerzo por abrirle paso a una Asamblea Nacional Constituyente con el fin de reencausar la democracia colombiana y buscarle una salida institucional a la cantidad de problemas que aquejaban a la nación colombiana (Dugas, et al, 1991: 187-195). Según palabras de Palacios:

La convocatoria y elección popular de una Asamblea Constituyente en 1990 es uno de los hitos de la política de fines del siglo XX. Su objetivo explícito: hallar formulas para que el Estado, gobernado por líderes honestos y competentes, 
pudiera asegurar la paz, liquidar la impunidad y ensanchar los ámbitos de la democracia participativa (Palacios, 2001: 353).

En esta Asamblea participaron, como lo recuerda Dugas, una gran variedad de sectores sociales "desde figuras políticas tradicionales, hasta personas que por primera vez incursionaban en la actividad proselitista, pasando por ex-guerrilleros, periodistas, indígenas, ecologistas, académicos, estudiantes, sindicalistas y cristianos, entre otros" (Dugas, et al, 1991: 194). Fruto de este proceso fue la Constitución política de 1991 que derogó la Constitución de 1886. Esta Constitución, para decirlo en otros términos, tiene como objetivo profundizar y consolidar la democracia colombiana. Para eso, en ella se instituyó la Democracia participativa, la Acción de tutela como herramienta jurídica eficaz para que los ciudadanos defiendan y protejan sus derechos fundamentales, el nuevo estatus del Estado colombiano como Estado social de derecho, la Acción popular, se cambió la figura del "estado de sitio" por la de estado de excepción o de conmoción interior, y se reforzó la protección y garantía de los derechos fundamentales de los individuos como: el derecho a la vida, el libre derecho a la personalidad, la libertad de cultos, la libertad de conciencia y de expresión, el habeas corpus, el derecho de petición, la libertad de cátedra, y la libertad política, entre otros. Pero, fundamentalmente, como sostiene Kalmanovitz:

La Constitución de 1991 se basó explícitamente en la soberanía popular: la legitimidad del Gobierno deriva de la representación del pueblo, lo cual permitió una mayor libertad de conciencia y el respeto a la práctica de religiones distintas a la católica. La nueva Constitución aumentó el poder del legislativo, fortaleció el poder judicial y les restituyó varios poderes a las organizaciones territoriales (Kalmanovitz, 2010: 310).

Obviamente, la Constitución de 1991 es una estructura institucional que por sí sola no ha sido capaz de poner freno al agudo y sangriento conflicto armado colombiano -en el cual participan como actores el Estado, las guerrillas, los paramilitares, el narcotráfico- que, a decir de muchos investigadores, es "en la actualidad uno de los pocos casos que restan en el mundo de lo que se ha denominado conflictos armados prolongados" 
(Pizarro, 2004: 29). Y que, en sus escasos veintidós años de historia, se ha visto asediada por sectores políticos tradicionales que la desean sepultar para volver a la Constitución de 1886 y por élites políticas que no creen en la nueva institucionalidad o por políticos profesionales que, por haber caído en la criminalidad de todo tipo -paramilitarismo, narcotráfico, corrupción, clientelismo, etc.-, ven en la Constitución de 1991 y en el tipo de vida democrática que ella representa y defiende, un obstáculo a la realización de sus intereses particulares. El contrapeso de este fenómeno es otro conjunto de políticos profesionales que realizan su labor desde la legalidad y el marco de la Constitución de 1991, y que con sus prácticas, valores, actitudes e ideales, contribuyen a la consolidación del tipo de vida democrática que emergió en Colombia a partir de la década de 1990.

\section{La dimensión de lo actitudinal en Gustavo Petro}

Características sociodemográficas

Gustavo Francisco Petro Urrego nació el 19 de abril de 1960 en Ciénaga de Oro, departamento de Córdoba, en una familia de fuerte tradición campesina. ${ }^{5}$ Justamente catorce años antes de que fuera fundado el Movimiento 19 de abril, grupo insurgente del que haría parte en su primera juventud. Hijo de Clara Nubia Urrego y de Gustavo Petro, educador. Desde muy niño su familia se trasladó a Zipaquirá, donde se levantó y se formó en sus primeros años de escuela. Estudió en el Colegio Nacional de La Salle de Zipaquirá. Allí creó el periódico llamado Carta al Pueblo y el Centro Cultural Gabriel García Márquez. Y, en esa institución, inicio su rechazo "a la religiosidad extrema de los sacerdotes del Colegio" . Leía a Marx, a Lenin y a García Márquez. Desde esa época, sostuvo Petro en una entrevista a El Espectador, "la política era la vida entera. Sin fiestas ni fútbol ni amores". 7 Se graduó a los 16 años del colegio y obtuvo uno de los mejores puntajes en las pruebas de Estado para el ingreso a los estudios universitarios. Ingreso a estudiar Economía en la Universidad Externado de Colombia, donde

\footnotetext{
5 Consultado desde: http://www.eldiario.com.co/seccion/POLITICA/un-abanico-de-candidatos100529.html

6 Consultado desde: http://www.elespectador.com/impreso/politica/articuloimpreso-202588-luchas-delcompanero-aureliano

7 Consultado desde: http://www.elespectador.com/impreso/politica/articuloimpreso-202588-luchas-delcompanero-aurelianoConsultado desde:
} 
estudio becado. A los 17 años, contactado por un maestro de Escuela, se unió al M-19, movimiento del que dijo en alguna ocasión: "el lenguaje del M-19 era absolutamente diferente al de la izquierda radical. Para mi fue un discurso refrescante, porque ya no quería estar en las discusiones entre trotskistas, maoistas, estalinistas ni mamertos". 8 Llegó a ser Personero de Zipaquirá en 1980, a la edad de 21 años; y Concejal independiente de ese municipio, entre 1984 y 1986, a los 24 años. Según ha sostenido Petro en varias entrevistas, esos cargos públicos los obtuvo gracias a que los habitantes del municipio lo conocían y lo apreciaban o, para decirlo con Blondel y Thiébaut, por su notoriedad, popularidad y carisma (Blondel y Thiébaut, 2010: 15-20).

Cuando finalizó sus estudios universitarios, en 1984, hizo público su vínculo con el grupo insurgente en una manifestación en la plaza de Zipaquirá. Desde ese momento pasó a la clandestinidad y a ser perseguido por el Estado. Su papel en el movimiento guerrillero no era militar sino de carácter ideológico - político y proselitista-. Se sabe que una de sus tácticas para evadir a las autoridades era disfrazarse. En octubre de 1985 fue capturado por el Ejército, iba vestido de mujer. Lo interrogaron, lo torturaron y lo sometieron a pena de prisión por dos años, acusado de porte ilegal de armas. Estando en prisión se produce la toma del Palacio de Justicia. En 1987 sale de prisión y se reintegra a la lucha insurgente, pero ahora, en medio de un nuevo ambiente político y con un lugar importante en la organización guerrillera, se dedica, junto a Carlos Pizarro Leongómez, a darle cuerpo al proceso de paz entre el M-19 y el gobierno de Belisario Betancourt. Proceso que culminará exitosamente y que será modelo para otros países de Latinoamérica. Tras desmovilizarse, funda con otros desmovilizados del M-19 el partido político Alianza Democrática M-19 (AD M-19) y participa, en 1991, "como asesor económico de la Asamblea Nacional Constituyente". ${ }^{9}$ Esa es su puerta de entrada desde la legalidad como político profesional. Retoma su vida académica y hace una Especialización en Administración Pública en la Escuela Superior de Administración Pública (ESAP). Una Maestría en Economía en la Universidad

8 Consultado desde: http://www.elespectador.com/impreso/politica/articuloimpreso-202588-luchas-delcompanero-aureliano

9 Consultado desde: http://www.elespectador.com/impreso/politica/articuloimpreso-202588-luchas-delcompanero-aureliano 
Javeriana. En Bélgica realizó una Especialización en Medio Ambiente y Desarrollo Poblacional en la Universidad Católica de Lovaina. Y, en España, un Doctorado en Nuevas Tendencias en Administración de Empresas, en la Universidad de Salamanca.

De 1990 a 1991 fue Asesor de la Gobernación de Cundinamarca. Con el apoyo del AD M-19 es elegido Representante a la Cámara en 1991. En 1994, amenazado de muerte, es nombrado agregado diplomático en Bruselas por el gobierno de Ernesto Samper. ${ }^{10}$ En 1998 vuelve a ser elegido, por el Movimiento Vía Alterna, como Representante a la Cámara. En el 2002 es elegido nuevamente como Representante a la Cámara, en esta oportunidad obtuvo la votación más alta a la Cámara (79 mil votos) y se convirtió en el congresista estrella del país por sus denuncias sobre la corrupción, el paramilitarismo, el narcotráfico y por su función de control político y oposición al gobierno del presidente Álvaro Uribe Vélez. Por el año 2006 fue elegido Senador de la República, en este periodo destapo la llamada parapolítica, el nexo entre los políticos profesionales del país y los paramilitares, y la denominada farcpolítica. En el año 2010 se lanzó como candidato a la presidencia de la Republica por el movimiento político Polo Democrático Alternativo (PDA), elecciones en las que fue derrotado por Juan Manuel Santos. En este mismo año Petro renuncia al PDA, denuncia el "cartel de la contratación" en Bogotá, que le cuesta la salida de la alcaldía a Samuel Moreno (miembro del PDA) y crea el Movimiento Progresistas. Con este último movimiento Petro se lanza como candidato a la Alcaldía de Bogotá, y resulta elegido el 30 de octubre de 2011, para el periodo 1 de enero de 2012 al 31 de diciembre de 2015, con el $32.22 \%$ de los votos.

Cabe destacar que durante su trayectoria como político profesional, en la legalidad, Gustavo Petro ha sido objeto de múltiples amenazas contra su vida por parte de grupos de ultraderecha y de la persecución de organismos de inteligencia y seguridad del Estado como el Departamento Administrativo de Seguridad (DAS) a quienes Petro denunció por seguir, acosar y expiar a miembros de la oposición al gobierno de Álvaro Uribe Vélez. Actualmente, mientras ejerce como Alcalde de Bogotá es objeto de una iniciativa de revocatoria de su mandato como Alcalde, instaurada por el representante a la Cámara Miguel Gómez Martínez, por críticas a la gestión en su Administración de parte de sus opositores políticos.

10 Consultado desde: http://www.lasillavacia.com/perfilquien/19496/gustavo-petro 
Tabla 1

Partidos politicos en los que ha militado Gustavo Petro

\begin{tabular}{|l|c|c|}
\hline \multicolumn{1}{|c|}{ Partido o Mov. político } & Ingreso & Salida \\
\hline Alianza Democrática M-19 & Julio 20 de 1991 & Julio 19 de 2004 \\
\hline Movimiento Vía Alternativa & Julio 20 de 1998 & Julio 19 de 2006 \\
\hline Polo Democrático Alternativo & Julio 20 de 2006 & Julio 20 de 2010 \\
\hline Movimiento Progresistas & Enero 01 de 2012 & \\
\hline
\end{tabular}

Fuente: elaboración propia.

Tabla 2

Cargos públicos ocupados por Gustavo Petro en su trayectoria política en la legalidad

\begin{tabular}{|l|c|c|c|}
\hline \multicolumn{1}{|c|}{ Cargo público } & Partido o Mov. político & Ingreso & Salida \\
\hline $\begin{array}{l}\text { Asesor de la Gobernación } \\
\text { de Cundinamarca }\end{array}$ & Alianza Democrática M-19 & 1990 & 1991 \\
\hline Representante a la Cámara & Alianza Democrática M-19 & Diciembre 12 de & Julio 19 de 1994 \\
\hline Representante a la Cámara & Movimiento Vía Alternativa & Julio 20 de 1998 & Julio 20 de 2002 \\
\hline Representante a la Cámara & Movimiento Vía Alternativa & Julio 20 de 2002 & Julio 20 de 2006 \\
\hline Senador de la República & Polo Democrático & Julio 20 de 2006 & Julio 19 de 2010 \\
\hline Alcalde Mayor de Bogotá & Movimiento Progresistas & Enero 01 de 2012 & \\
\hline
\end{tabular}

Fuente: elaboración propia.

Ideales, valores y actitudes en términos de la consolidación de la democracia

En las fuentes consultadas para este trabajo sobre las percepciones, ideales, creencias, valores, actitudes y orientaciones políticas de Gustavo Petro, en la lógica de la consolidación y la valoración de la calidad de la democracia, encontramos los siguientes datos:

\section{Primero}

En términos de la manera de concebir la democracia Petro, como buen hijo de la Asamblea Nacional Constituyente, la define desde el espíritu de la Constitución política de 1991 y resalta los principios de "separación de poderes, libertad de expresión y absoluto respeto al libre emprendimiento, al trabajo en Colombia” (El Espectador, febrero 14, 2010. Sec- 
ción Política, p. 6). Desde esta óptica Petro define lo que él llama la democracia del siglo $X X I$, una manera de distanciarse del proyecto político que, en su momento, lideraba Hugo Chaves en Venezuela y del de la guerrilla de las FARC en Colombia. De igual forma, para distinguir su idea de la democracia de la de proyectos radicales de la extrema derecha o de la extrema izquierda, Petro defiende la idea de que para llegar al poder hay que valerse de los medios legales que brinda la Constitución política de 1991, según él:

\footnotetext{
No todas las formas de lucha son válidas, porque el fin ya no justifica los medios. Todos los medios y formas de lucha que sean coherentes con el fin establecido son más coherentes si queremos una democracia pacífica y moderna en Colombia. Mis medios deben ser democráticos, pacíficos y modernos ( $E l$ Espectador, febrero 14, 2010. Sección Política, p. 6).
}

El mensaje que el otrora guerrillero del M-19 envía a sus seguidores y copartidarios políticos es que se deben defender y respetar los principios del Estado Social de Derecho establecidos por la Constitución de 1991. Y, sobre todo, el uso de medios legales para alcanzar el poder. Ya paso el tiempo de la toma del poder por medio de las armas. Ahora en la legalidad Petro defiende los medios legales, pacíficos y "modernos".

\section{$\underline{\text { Segundo }}$}

Ideológicamente Petro se define como un demócrata. Es decir, no como un comunista sino, más bien, en la forma como se ha de definir un demócrata quien defiende la Constitución de 1991. Tomando como contradictor a la guerrilla de las FARC, Petro afirma:

\footnotetext{
Las FARC son comunistas, yo soy un demócrata. Las FARC decidieron en 1989 continuar en armas, yo las dejé; las FARC luchan contra la Constitución del 1991, yo soy el principal defensor de la Constitución de 1991; las FARC se han degradado como criminales de guerra, yo creo que ni siquiera el uso de las armas puede permitir la degradación del ser humano hasta ese nivel de barbarie (El Espectador, febrero 14, 2010. Sección Política, p. 6).
}

Su deslinde de un grupo como las FARC es un modo de legitimar su actividad política en la legalidad y, en el fondo, una manera de ayudar a legitimar el entramado institucional 
que le dio la entrada a la actividad política y que le garantiza esa su actividad. Pero Petro también tiene que autodefinirse ideológicamente en algunos momentos de su trayectoria política, esto a razón de las intensas luchas por el poder entre los partidos y en el interior del partido político del que él, en algún momento, hizo parte, el Polo Democrático Alternativo. En estas circunstancias y por la naturaleza y el origen ideológico del Polo Democrático Alternativo, partido compuesto por distintos sectores y tipos de la izquierda en Colombia -unos más radicales que otros-, Petro se autodefine como de centro-izquierda. Él dice:

\footnotetext{
Soy una especie de centro en el Polo. Pero ahora todo cambia, porque los puntos de referencia se desplazan. A mí me ponían antes en el radicalismo y ahora me ponen en la derecha. Incluso ciertos amigos del Polo han llegado a escribir que soy el uribista del partido. Ese es un juego muy complejo y el Polo apenas se está configurando (El Espectador, 6A, 3-9 febrero de 2008).
}

Es interesante ver cómo esta manera de autodefinirse coincide con su relato de que una de las razones que lo llevaron a formar parte del M-19 consistió en que esta guerrilla no profesaba un discurso de izquierda radical. Según él, el "espíritu dogmático, sectario y antidemocrático" de la izquierda tradicional le causa repulsión (El Espectador, junio 15 de 2008, Sección Política, pp. 14-15). Ahora bien, al definirse en el espectro político como de centro-izquierda, Petro se autodefine como un político ideológicamente pluralista e incluyente. Para él "la izquierda debe trabajar por reconstruir el diálogo político, como ya lo hizo con la Constitución del 1991" (Revista Cambio, Sección Diez preguntas, junio 04 de 2009, p. 30). Aún más, piensa que "la izquierda se vuelve más fuerte si es capaz, mediante reglas de juego objetivas, de construir acuerdos con otros sectores democráticos que incluyan su programa, que no es otro que acabar con la violencia, disminuir la desigualdad y salir de la pobreza” (Revista Cambio, Sección Diez preguntas, junio 04 de 2009, pp. 30-31).

\section{Tercero}

En relación con el respeto y la confianza en las leyes e instituciones, un tema de importancia para la consolidación de la democracia, Petro dice ser, todo el tiempo un defensor de la Constitución política de 1991. Y en sus entrevistas en los medios y 
alocuciones su mensaje a sus copartidarios, y a la ciudadanía en general, es el respeto y la confianza por la carta constitucional de los colombianos. En su propia lógica, "el Polo (su partido político) se creó para ser el partido de la defensa de la Constitución del 91. Pero se lo tomaron las mafias y no quisieron quitárselas de encima" (El Espectador, mayo 11 de 2008. Sección Bogotá). Incluso, haciendo a un lado su difícil relación con las Fuerzas militares colombianas, por su pasado guerrillero, Petro alienta a la ciudadanía a tener confianza y respeto por las fuerzas militares. Para él, "quienes eran dignos rivales se pueden estrechar la mano y construir una cooperación común. No hay nadie que pueda entender mejor las fuerzas militares que Petro" (El Espectador, febrero 14, 2010. Sección Política, p. 7). Eso sí, también exige una "fuerza pública sin mafias internas, depurada de corruptos, respetuosa al máximo del derecho de gentes" (El Espectador, abril 12 2009, p. 10).

\section{Cuarto}

De distintas maneras Petro hace saber su falta de confianza en los partidos políticos en Colombia, a raíz de la crisis por la que estos atraviesan. Fundamentalmente en lo que corresponde con su propio partido, al cual renunciara después de los bochornosos escándalos de corrupción, de los que se inculpó, entre otros, a Samuel Moreno Rojas alcalde de Bogotá por el Polo Democrático Alternativo para el periodo 2008-2011. Hechos de corrupción que el propio Petro ayudó a denunciar en su momento. La actitud de Petro en este sentido es de constantemente crítica respecto de los partidos tradicionales y de los de izquierda. En la información recabada se encuentra un rechazo por el bipartidismo colombiano y un deseo de superar ese viejo esquema. Y la salida de Petro a esta tradición bipartidista es la construcción de un sistema pluripartidista:

\footnotetext{
Pienso que hoy existen cuatro grandes fuerzas que podrían -por ahora- integrar esa convergencia: el Polo Democrático, el Partido Liberal, las fuerzas independientes (Sergio Fajardo, Antanas Mockus y otros por el estilo) y las fuerzas sociales compuestas por las centrales obreras, los movimientos de indígenas y demás. Aquí podrían caber incluso hasta los sectores que pertenecieron al uribismo y se han desilusionado y también pueden aportar a la iniciativa. Esto pensando en un futuro previsible (El Espectador, enero 06 2009, Sección Política, p. 9).
} 
En este sentido la actitud de Petro es el de un ciudadano crítico de los partidos. Pues, al parecer, para él los partidos deben estar supeditados a la Constitución y al orden jurídico, y no por encima de la ley de leyes. Así lo hace saber en sus críticas a su propio partido en el año 2010: "el Polo se creó para ser el partido de la defensa de la Constitución de 1991. Pero se lo tomaron las mafias y no quisieron quitárselas de encima" (El Espectador, febrero 14 de 2010, Sección Bogotá, p. 6). Y, obviamente, tiene muy poca confianza en la honestidad y democratización de los partidos en Colombia, empezando por su propia organización política a la que, además de denunciar las relaciones entre el clientelismo y la izquierda, la falta de coherencia ideológica, el sectarismo, la inequidad, le critico públicamente por haber caído en prácticas de corrupción: "para mí, el brazo político del cartel de la contratación en Bogotá fue el Partido de la U en el Concejo. El Polo tiene una responsabilidad política porque hoy dos de sus militantes están inmersos en el tema del cartel y no son cualquiera: el alcalde y su hermano" (El Espectador, mayo 8 2011, Sección Política, pp. 14-15). Y, aún más, sostiene que él:

Del Polo esperaba otra cosa. Pensé que iban a sacar la corrupción de sus filas. Pero hasta hoy no han sido capaces de expulsar a los Moreno y Rojas. Y no lo han hecho por dos razones: por el clientelismo, que viene de los sectores afines al samperismo; y por el sectarismo de la izquierda tradicional, que trastocó un proyecto democrático y pluralista (Revista Semana, Sección “En plata blanca”, julio 25 de 2011, pp. 36).

Quinto

Para Petro la crisis de los partidos políticos es un problema grave del país y de la política colombiana. Pero, obviamente, no es el único. Uno de los más graves es la relación entre "política-narcotráfico-paramilitarismo". Ese es uno de los ejes del mal para Petro en Colombia.

Lo cierto es que el problema más grave que tiene la política colombiana es su articulación con el narcotráfico y por eso hice énfasis en mis últimos años de vida parlamentaria en este tema, el principal, el más peligroso de todos y el que debe ser superado de inmediato (El Espectador, febrero 14, 2010. Sección Política, p. 6).

Este eje del mal, este vínculo "política-narcotráfico-paramilitarismo", ha llevado a la cooptación del poder político y del Estado en manos de estos sectores de la ilegalidad: 
Lo que muestran los últimos datos, y por eso se exilió la fiscal antimafia, es que los jefes del narcoparamilitarismo no están por fuera del Estado, sino adentro. Como se dijo en Ralito: refundaron la patria y hoy son congresistas y miembros de la fuerza pública. Por eso la pregunta es: ¿cuál va a ser la política contra el neo-paramilitarismo? (El Espectador, marzo 13 2008, Sección Política, p. 17).

Petro piensa que este es uno de los grandes males que hay que erradicar. Y cree que: "si soy algún día presidente, ese será el día de la hecatombe de las mafias y de la resurrección de la democracia” (El Espectador, noviembre 04, 2008, Sección Política p. 7). Aunado a esto, considera que otros de los grandes problemas de la democracia colombiana son la guerrilla, el conflicto armado, la corrupción y la pobreza. Sobre este último problema social dijo en octubre de 2010:

Estamos hablando de millones de personas víctimas, empobrecidas a la fuerza e incluso en estado de indigencia, o como dice la Corte, en un estado inconstitucional de cosas, que de superar ese situación implicaría un salto de superación de pobreza e inequidad muchísimo más grande que cualquiera de los que se han dado en décadas (El Espectador, octubre 10 2010, Sección Política, pp. 16).

\section{La dimensión de lo actitudinal en Antanas Mockus Šivickas}

\section{Características sociodemográficas}

Aurelijus Rutenis Antanas Mockus Šivickas nació el 25 de marzo de 1952 en Bogotá, Colombia. Es hijo de Alfonsas Mockus y la escultora y ceramista Nijole Šivickas de Mockus, inmigrantes lituanos. Se dice que su padre Alfonsas, quien le enseño matemáticas, se hizo ingeniero por correspondencia de dos universidades norteamericanas. ${ }^{11}$ Sus padres padecieron los efectos de la segunda Guerra Mundial. En una entrevista a El Espectador Antanas relato: “mis padres sufrieron la guerra por ambos lados, tanto la invasión alemana como la rusa, la profesora más cercana a nosotros fue fusilada, mi abuelo fue desterrado a un gulag en Siberia". ${ }^{12}$ Su padre murió en un accidente aéreo viajando de Cartagena a Bogotá, hecho trágico que dejó a Antanas con una crisis

11 Consultado desde: http://www.lasillavacia.com/perfilquien/19416/antanas-mockus

12 Consultado desde: http://www.elespectador.com/impreso/antanas-mockus/articuloimpreso201018antanas-mockus-lituano 
emocional. Estudió en el Liceo Francés de Bogotá, donde se graduó en 1969. Estudió Matemáticas y Filosofía en la Universidad de Dijon, Francia, en 1972. En esta misma universidad y año inicia sus estudios de Maestría en Matemáticas. Más tarde, en 1988, realiza una Maestría en Filosofía en la Universidad Nacional de Colombia. Además del castellano, habla lituano, inglés, francés y polaco. Ha navegado por las obras de Kant, Heidegger, Foucault, Lyotard y Deleuze. Fue profesor de la Universidad Nacional de Colombia a partir de 1975.

En la década del 1980 fue miembro y director del Grupo de Investigación Federici, experiencia que va a ser decisiva en sus propuestas y planteamientos como político profesional, pues este grupo liderado por el profesor Carlo Federici se enfocó a la investigación de la enseñanza de las ciencias, la educación y a defender y desarrollar la tesis de que "el desarrollo de una actitud científica en los niños puede contribuir al desarrollo de competencias ciudadanas que permitan la construcción colectiva de una sociedad democrática y la formación personal y, por otro lado, que la formación ciudadana puede proveer herramientas para la formación de una actitud cientifica". ${ }^{13}$

En 1990 es nombrado Rector de la Universidad Nacional de Colombia y es a partir de aquí que se hace una figura pública en Colombia por su notoriedad, popularidad $y$ carisma (Blondel y Thiébaut, 2010: 15-20). Pero más que por su cargo de rector, por sus excentricidades. Una de ellas, la que prácticamente lo catapultó a la fama en el concierto nacional, fue cuando siendo Rector, en el Auditorio León de Greiff ante un número de 1.000 estudiantes, se bajó los pantalones y les mostró el trasero en protesta porque no lo dejaban hablar. Su trasero lo hizo uno de los hombres más famosos de Colombia pero fue, a la vez, el que lo dejo sin el cargo de Rector.

Entonces, se puede decir - parafraseando a Machiavelli- ${ }^{14}$ que ese acto audaz e irrespetuoso de Mockus fue el que le atrajo los favores de la fortuna. Pues, a partir de ese momento deja a un lado la vida académica y se convierte en político profesional. Cuando en 1993 tuvo que renunciar a la rectoría de la Universidad Nacional, Gustavo Petro "le aconsejó a Mockus lanzarse como candidato a la Alcaldía, una idea que a nadie más y

13 Consultado desde: http://www.grupofederici.unal.edu.co/proyectos/index.html

14 Machiavelli, 1971. 
mucho menos a Mockus se le había ocurrido". ${ }^{15}$ Ahora la fortuna los unía, años después los convertiría en aguerridos rivales políticos, sin dejar de ser amigos. Sin maquinaria política ni recursos económicos suficientes, y apoyado sólo en las tesis de Federici y de su grupo de investigación sobre la cultura ciudadana, el 1 de enero de 1995 Mockus se posesiona como alcalde de Bogotá. Su gobierno y administración basada en la cultura ciudadana -construcción y fortalecimiento de vínculos sociales, desarrollo de virtudes cívicas como el respeto por las leyes, la institucionalidad y el bien público, a través de campañas pedagógicas- resultó siendo muy exitosa y a la vez sui generis. Mockus saneó las finanzas de la ciudad, redujo la violencia, prohibió el uso indiscriminado de pólvora en las fiestas de fin de año para evitar la historia de miles de niños quemados. Implementó la hora zanahoria, una estrategia de cultura ciudadana para evitar las muertes en accidentes de tránsito por la ingesta de altas cantidades de alcohol en los bares de la ciudad. También implementó un "plan desarme" y una campaña de "ahorro voluntario de agua". Además de todo lo anterior, se casó en un circo, a lomo de elefante y en una jaula de tigres, con Adriana Córdoba, una trabajadora social veinte años menor que él.

En 1997 renuncia a la alcaldía de Bogotá para participar en las elecciones presidenciales de 1998. Tras su renuncia tuvo que trabajar dando conferencias y haciendo reportajes para noticieros de televisión con tal de poder subsistir. En esa campaña torno a sus excentricidades. En un acto público televisado, arrojó un vaso de agua sobre la cara del candidato presidencial por el Liberalismo Horacio Serpa con el fin de ilustrar uno de sus métodos de cultura ciudadana. Su idea era que Serpa tolerara la broma, pero esta vez el método no funcionó. En el año 2001 vuelve a ser Alcalde de Bogotá, una segunda administración que vuelve a ser exitosa y le da el capital político suficiente para aspirar a la presidencia de la República. Con estas intenciones crea el Movimiento Visionarios para las elecciones al Congreso del año 2006, con muy malos resultados. Pese a la derrota sigue en campaña presidencial en ese mismo año y queda cuarto en una contienda donde Álvaro Uribe Vélez es reelegido como presidente. En el año 2009 empieza a militar en el Partido Verde al lado de Luis Eduardo Garzón y Enrique Peñalosa -ambos ex-alcaldes de Bogotá-. En consulta popular del Partido Verde, en el 2010, Mockus resulta elegido como candidato

15 Consultado desde: http://www.lasillavacia.com/historia/mockus-y-petro-tan-lejos-tan-cerca-27132 
único del partido a la presidencia de la República. En esa contienda, en la primera vuelta, Mockus obtuvo la segunda votación más alta (21.49\%), siendo el candidato más votado Juan Manuel Santos quien, en segunda vuelta, derrotó a Mockus el 20 de junio de 2010. Pero Mockus obtuvo 3.588.819 votos el $27.5 \%$ de los sufragios. ${ }^{16}$

Si bien en el año 1995, para seguir usando la terminología de Maquiavelo, la fortuna le era favorable y le daba con gracia sus favores, en el mes de abril del año 2010 la fortuna, esa diosa que los antiguos romanos representaban como una mujer con los ojos vendados y una ruleta en una de sus manos, le voltea caprichosamente la espalda. En la etapa más álgida y favorable de la campaña para Mockus, el filósofo y matemático y, ahora, exitoso candidato presidencial es diagnosticado con la enfermedad de párkinson. Los medios de comunicación del país comentaron así, el 10 de abril de 2010, la mala fortuna de Mockus:

\begin{abstract}
La noticia de que Antanas Mockus sufre del mal de Parkinson provocó un enorme impacto en la opinión pública y se convirtió en el tema del día en todos los medios. El propio Mockus fue el que dio la noticia. En la misma entrevista, en La W, en la que le daban la chiva de que estaba a escasos 5 puntos del puntero Juan Manuel Santos, el ex alcalde, con la franqueza que lo caracteriza, ante una pregunta sobre los rumores que circulaban sobre sus problemas de salud admitió que sufre esa enfermedad. ${ }^{17}$
\end{abstract}

En ese momento, Mockus además de reconocer que ya padecía la enfermedad intentó calmar a su electorado diciendo que sus médicos le habían dicho que esta no "afecta las actividades mentales. El pensamiento, la creatividad, el conocimiento funcionan perfectamente bien. Hay algo de temblor en las manos que alguna gente notó. El pronóstico son 12 años o más de vida normal gracias a la medicación”. " Haciendo un llamado a sus seguidores y copartidarios dijo: "entiendo la preocupación ciudadana, pero espero que no me crucifiquen por una enfermedad que me afecta en lo fisico y no en lo mental". ${ }^{19}$ Sin embargo, estas palabras no eran más que el presentimiento de que, en esta ocasión, la buena fortuna lo había abandonado.

\footnotetext{
16 Consultado desde: http://www.lasillavacia.com/perfilquien/19416/antanas-mockus

17 Consultado desde: http://www.semana.com/nacion/articulo/el-problema-del-parkinson/115355-3

18 Consultado desde: http:/www.semana.com/nacion/articulo/el-problema-del-parkinson/115355-3

19 Consultado desde: http://www.semana.com/nacion/articulo/el-problema-del-parkinson/115355-3
} 


\section{Tabla 3}

Partidos políticos en los que ha militado Antanas Mockus

\begin{tabular}{|l|c|c|}
\hline \multicolumn{1}{|c|}{ Partido o Mov. político } & Ingreso & Salida \\
\hline Visionarios por Colombia & 2006 & \\
\hline Alianza Social Indígena & 2006 & 2011 \\
\hline Partido Verde & 2010 & \\
\hline Alianza Social Independiente & 2011 & \\
\hline
\end{tabular}

Fuente: elaboración propia.

Tabla 4

Cargos públicos ocupados por Antanas Mockus en su trayectoria política

\begin{tabular}{|l|c|c|c|}
\hline \multicolumn{1}{|c|}{ Cargo público } & Partido o Mov. político & Ingreso & Salida \\
\hline Alcalde Mayor de Bogotá & Independiente & 1995 & 1997 \\
\hline Alcalde Mayor de Bogotá & Independiente & 2001 & 2003 \\
\hline
\end{tabular}

Fuente: elaboración propia.

Ideales, valores y actitudes en términos de la consolidación de la democracia

En las fuentes consultadas para este trabajo sobre las percepciones, ideales, creencias, valores, actitudes y orientaciones políticas de Antanas Mockus, en la lógica de la consolidación y la valoración de la calidad de la democracia, encontramos los siguientes datos:

\section{Primero}

Consecuentemente con su bandera sobre la cultura ciudadana para Mockus la democracia significa, ante todo, participación y contradicción política entre partidos. En esto su idea de la democracia está muy cercana a los ideales del liberalismo republicano. Y Mockus advierte que ese tipo de democracia está instaurada en la Constitución política de 1991, aunque con algunos riesgos.

Lo bonito de la Constitución del 1991 fue la posibilidad de que individuos como yo incursionáramos en la política con la facilidad. Sin embargo, esa puerta tan abierta traía ciertos riesgos. Ahora se está cerrando y cada vez es más difícil que un independiente participe en las elecciones. De algún modo, llegamos a la idea de que la democracia requiere competencia entre más 
partidos más que competencia entre individuos (El Espectador, septiembre 06 de 2009. Sección Entrevista. P. 16).

Por supuesto, en estas coordenadas de un liberalismo republicano no puede hacer falta el llamado a la veeduría popular sobre el gobierno y los gobernantes. Y ese componente está presente en los valores democráticos de Mockus, pues según él: "los ciudadanos tienen que ejercer presión sobre los líderes. Tienen que expresar las emociones de rechazo y volverlas efectivas. Tienen que asumir la defensa del derecho a la vida, que está en la Constitución" (El Espectador, mayo 11 de 2008. p. 20). De paso, este es un llamado a la ciudadanía a vigilar el bien público y, sobre todo, a defender sus derechos y libertades constitucionales. Lo que muestra que en el discurso sobre la democracia de Mockus, desde la óptica de la cultura ciudadana, sin un desarrollo de las virtudes cívicas en los ciudadanos no es posible la preservación y el respeto por el orden constitucional, ni la garantía de las libertades de participación política.

\section{Segundo}

En el tema del respeto y la confianza en las leyes e instituciones, da la impresión de que Mockus siguiera de cerca, o se inspirara, en la idea de capital social usada por Putnam para su investigación en Bowling Alone: The Collapse and Revival of American Community (2000). Pues lo que él propone no es otra cosa que "una política basada en la confianza basada entre las personas y las instituciones" como un modo de transformar la manera de hacer política en Colombia (El Espectador, marzo 09 de 2010. Sección Voto 2010, p.4). Para Mockus es como si el respecto a las leyes e instituciones sólo fuera posible desde el fortalecimiento de los vínculos sociales, es decir, desde la consolidación de una moralidad pública lo suficientemente fuerte como para que se produzca la auto-regulación social. A este respecto, en una entrevista en mayo de 2012, afirmó lo siguiente: "en Colombia la gente entiende la lealtad como algo muy personal. Sociedades más fuertes ponen la lealtad al lado de la institucionalidad. Cuando hay una comunidad moral lo que empieza a haber es reproches" (Revista Semana, Sección Entrevista, mayo 21 de 2012, p.14). Desde este punto de vista, Mockus lo que hace es plantear una fuerte crítica a la naturaleza y el estado de la ética pública en la sociedad colombiana. En especial a la clase política por su falta de virtud y compromiso cívico, al punto que en alguna ocasión la asimila a la guerrilla de las FARC. 
La clase política es igual de desalmada, de cruel y de obstruccionista que las FARC, guerrilla que pertenece por eso mismo a la Colombia vieja. La clase política sabe que el país la desprecia y que en ciertos momentos la condena pero nada de eso le importa porque tiene el poder real en sus manos (Revista Semana. Sección "En plata blanca", agosto 20 de 2012, p. 45).

Pero, también, es optimista con lo alcanzado en parte en sus dos administraciones como Alcalde de Bogotá:

\begin{abstract}
Bogotá aumentó la confianza en los alcaldes, es cierto. Pero también aumentó la confianza en las instituciones, en los servicios que presta el Distrito e incluso en la imagen del funcionario mismo. Ese es un buen ejemplo. Por el contrario, los costos de la desconfianza son enormes (El Espectador, 17 noviembre de 2008, p. 24).
\end{abstract}

Aún así, no cesa en su trayectoria política de llamar a la ciudadanía a ser leales y respetuosos con la institucionalidad democrática, con las instituciones y los funcionarios públicos. En la elecciones presidenciales de 2010 sostiene que él va "consolidar gerencial y pedagógicamente la seguridad democrática. Y abrirle espacio a la legalidad democrática”. Porque, para él, "el Estado de Derecho se plasma en el respeto a la policía y las fuerzas armadas, pero también se plasma en el respeto al fiscal y al juez" (El Espectador, marzo 09 de 2010. Sección Voto 2010, p. 4).

\title{
Tercero
}

Tal como era de esperarse, en un discurso fundado en la idea de la cultura ciudadana y de las virtudes cívicas, uno de los problemas más graves de la democracia colombiana para Mockus es el de las malas costumbres, los malos hábitos y perniciosas prácticas de los ciudadanos. En estos términos el gran lunar de la democracia colombiana está en la corrupción. Son muchas las entrevistas, declaraciones y documentos de la trayectoria política de Mockus en las que este es el tema recurrente. En algún momento de su trayectoria política, Mockus declaro que:

Entre todos y todas podemos corregir costumbres equivocadas. El 'atajismo', la cultura del vivo, el confundir derechos con favores, la corrupción y la violencia sobrevi- 
ven porque existen ámbitos sociales o culturales donde esos fenómenos se arraigan y se vuelven regla puesto que encuentran respaldo en conglomerados compartidos de creencias, justificaciones y hábitos (Revista Semana, sin año, p. 25).

Refiriéndose a los logros de sus dos administraciones como alcalde de Bogotá, expresó en el año 2011 lo siguiente:

\begin{abstract}
Nosotros cerramos las puertas del clientelismo y algunos de los políticos locales la abrieron otra vez y por allí se metió la corrupción con toda su fuerza. Fueron elecciones en las cuales el acceso al gobierno nació contaminado de corrupción no solo por el apoyo a las campañas por parte de contratistas, sino porque eso se volvió una asociación para delinquir (El Espectador, septiembre 25 de 2011, Sección Bogotá, pp. 30-31).
\end{abstract}

En las elecciones para presidente de la República de 2010, poniendo sus esperanzas en las virtudes de la ciudadanía, afirmó que:

El clientelismo no tendrá espacio en mi gobierno, ni usaremos el soborno, ni acep-
taremos el chantaje legislativo. En caso de que un proyecto sea objeto de obstruc-
ción esperaremos que la opinión pública se pronuncie y ejerza formas democráti-
cas de presión social (El Espectador, marzo 09 de 2010. Sección Voto 2010, p. 4).

No se puede desconocer que si bien, para Mockus, el gran problema de la democracia colombiana es el de la cultura ciudadana o, mejor, el del debilitamiento o ausencia de las buenas costumbres cívicas, para él también existen otros problemas estructurales a los que se les deben hacer frente como, por ejemplo, la guerrilla, el conflicto armado, el narcotráfico, el consumo de drogas, la inequidad de género y la pobreza, para la cual propuso en el 2010 "redistribuir los ingresos y la riqueza: para ello hay que aumentar el ingreso por habitante y adoptar una politica fiscal progresiva" (El Espectador, marzo 09 de 2010. Sección Voto 2010, p. 4). Pero, en términos generales, Mockus muestra una gran confianza en el respeto por la legalidad y en el poder de la educación como instrumentos para la construcción de una sociedad mejor y para la consolidación de la democracia en Colombia. 


\section{Conclusiones}

Una vez develado la dimensión de lo actitudinal en Mockus y Petro, el cual era el objetivo general de este trabajo, ahora en las conclusiones nos ocuparemos de los objetivos específicos. Por eso, en primer lugar, con base en los datos recopilados, se plantearan las semejanzas y diferencias en la dimensión de lo actitudinal entre Mockus y Petro; y, en segundo lugar, se argumentará cuáles son los aportes de ambos políticos a la consolidación de la democracia en Colombia desde sus percepciones, ideales, creencias, valores, actitudes y orientaciones políticas.

\section{Semejanzas y diferencias en la dimensión de lo actitudinal en Mockus y Petro}

A Petro y a Mockus los unen y separan varias cosas. Ambos fueron por muchos años outsiders de la política profesional. Petro se hace político profesional a la edad de 31 años y Mockus a los 41. Su llegada a la política profesional no estuvo respaldada por herencias familiares, poder económico, influencias de apellidos, partidos o maquinarias políticas. Su éxito se debe a su propio tesón, su trabajo académico y universitario, y a su especial sintonía con sus copartidarios y la ciudadanía en general. Sin embargo, su entrada a la política profesional también se debe a las nuevas circunstancias político-institucionales de Colombia en los inicios de la década de 1990, en particular a la Constitución política de 1991. Este hecho Petro y Mockus siempre lo han reconocido, por eso ellos nunca han dejado de plantearse como defensores de la Constitución política de 1991. Se consideran prácticamente hijos de esa Constitución y de sus valores y principios democráticos. En este sentido, ellos se consideran pertenecientes a la "nueva Colombia" y no a la "vieja". Pues la vieja representa un pasado trágico e injusto, lo tradicional, el bipartidismo, la Violencia, el Estado confesional, el clientelismo, la corrupción, la mafia, la desigualdad social, el autoritarismo, la exclusión social, racial y de género.

Ellos y la Constitución de 1991 son la "nueva Colombia". Por eso, ambos coinciden en deslegitimar a la vieja clase política del país, sus malas costumbres, sus perniciosas prácticas sociales $\mathrm{y}$, ante todo, sus nuevos y fuertes vínculos con el narcotráfico, el paramilitarismo y el crimen organizado. Y se sienten con la suficiente autoridad moral para descalificar lo que perciben como una clase política anacrónica con la nueva realidad del país porque, pese al pasado guerrillero del uno y a las excen- 
tricidades del otro, sus carreras políticas han sido transparentes y sus hojas de vida son impolutas. Por eso, ellos concuerdan en el esfuerzo y el ideal de una nueva forma de hacer política en Colombia, es decir, en un ejercicio de la política desde la legalidad, la honestidad, el respeto, la meritocracia y sin la intermediación de negociaciones y chantajes burocráticos. En fin, ambos se consideran demócratas, defensores de lo público, pluralistas, inclusivos, respetuosos del Estado de Derecho, amantes de la paz y del uso de medios pacíficos para la solución de los conflictos.

Si los anteriores aspectos nos muestran coincidencias entre estos dos políticos, la información recolectada nos da pistas sobre elementos que los separan. Mockus es ante todo un académico, salió de la academia para la política profesional, y en su trayectoria política ese espíritu no lo ha perdido. Petro es un hibrido entre el mundo de la política y el mundo de la academia. Antes de ser político profesional, mientras ejercía de ideólogo del M-19 cursaba estudios universitarios. Pero, al final, lo político se superpuso a lo académico en él. Esto, de algún modo, se filtra en sus creencias y posturas ideológicas. Mockus nunca ha sido de izquierda, seguramente por prevenciones a partir de la experiencia de su familia en Lituania. Sus posturas son, más bien, de derecha, pero no de una derecha radical o extrema sino cercana a lo que aquí hemos llamado un liberalismo republicano. Mientras que Petro se formó en la izquierda, pero en una izquierda moderada, de centro, como él gusta en decir. Estas diferencias ideológicas se evidencian en varios ámbitos de sus propuestas y proyectos políticos. Para Mockus la política es inconcebible sin pedagogía, sin educación. Eso explica que su gran bandera, durante toda su trayectoria política, haya sido la cultura ciudadana, es decir, la apuesta por la creación y fortalecimiento de vínculos sociales y el fomento de una ética de lo público que sirva de respaldo y de fundamento de las instituciones democráticas. En relación con las empresas del Estado Mockus está abierto a la idea de que estas puedan estar administradas por manos privadas o, incluso, de que se puedan privatizar.

Del mismo modo, es de la idea de que un mejor nivel de vida para los ciudadanos sólo es posible a través de altos niveles de tributación y de pagos de impuestos por parte de los mismos. Pagar para recibir. Por su parte para Petro, más que la educación o la cultura ciudadana, lo urgente para consolidar la democracia es disminuir la desigualdad social y acabar con la pobreza. En esto su postura es el de una democracia 
tirada a la centro-izquierda, que busca la justicia social. Por eso, es posible sostener que él no está de acuerdo con el lema "pagar para recibir" sino, más bien, con el de "recibir del Estado por medio de la redistribución económica o del buen manejo de los recursos económicos". Es decir, Petro defiende la idea de que el Estado es el que debe garantizar los derechos sociales y económicos de los ciudadanos. Una postura a lo Marshall (2007). Esto, de otro lado, indica que para Petro lo público no es privatizable ni puede estar en manos de los particulares, lo cual no lo pone de parte de un modelo de economía estatista.

\section{Aportes de Mockus y Petro a la consolidación de la democracia en Colombia}

Ya para finalizar, hemos de decir que la información recabada para este trabajo nos permite enunciar algunos importantes aportes que han hecho Petro y Mockus desde la dimensión de lo actitudinal a la consolidación de la democracia colombiana. Para empezar es necesario afirmar que, tal vez, el aporte más importante de estos dos políticos profesionales ha sido el haber insistido hasta la saciedad, desde el inicio de sus carreras políticas hasta el presente, en la importancia de fortalecer y defender la ética pública. Esto resulta de gran valor en una sociedad infestada por todo tipo de corrupción y, sobre todo, en una sociedad en la cual un discurso de esta naturaleza es impopular y hasta visto con escepticismo por la ciudadanía. También es un aporte fundamental, aun a contracorriente de fuertes sectores políticos tradicionales -amparados en el poder del dinero, de las mafias, de la maquinaria del partido- y de amenazas de muerte en contra de ellos, su defensa irrestricta de la legalidad, del respeto al Estado de Derecho y de la Constitución política.

No puede negarse tampoco que su actitud crítica frente a la clase política tradicional, el narcotráfico, el paramilitarismo y la corrupción, es un gran ejemplo de virtud cívica en una sociedad en donde hacer oposición se paga con la vida. Así mismo, el mismo hecho de que en una trayectoria política de más de veinte años estos dos políticos profesionales se hayan mantenido al margen de prácticas ilegales, criminales y corruptas para lograr sus fines, aun en contra de su propio éxito político, es una voz de aliento a la ciudadanía pues son el vivo ejemplo de que sí es posible de hacer política de otra manera en el país. Con esto no se quiere decir o argumentar que todo 
en la dimensión de lo actitudinal de Mockus y Petro es positivo, pues hay rasgos de su carácter poco loables que son de conocimiento público -como el autoritarismo deontológico de Mockus y el autoritarismo administrativo de Petro-, y otros que tal vez desconocemos. Pero, independientemente de esto, quizá su más grande aporte a la consolidación de la democracia en Colombia es haber hecho añicos la máxima de Maquiavelo de que "un hombre que quiera hacer en todas las cosas profesión de bueno, conviene que se arruine entre tantos que no son buenos" (Machiavelli, 1971: 279). ${ }^{20}$ Pues, Petro y Mockus han hecho "profesión de buenos" en un mundo en donde un alto porcentaje de políticos profesionales han decidido seguir el camino del mal. Y, pese a eso y a los reveses de la fortuna, no se han arruinado ni han dado el brazo a torcer.

\section{Bibliografía}

ALCÁNTARA, Manuel (2012). El oficio de político. Madrid: Editorial Tecnos.

BLONDEL, Jean (2010). "A Plea for a Genuine 'Micro-political' Analysis in Political Science”. En: Government and Opposition, Vol. 45, No. 4, pp. 553-593.

BLONDEL, Jean y Thiébaut, Jean-Louis (2010). Political Leadership, Parties and Citizens. The personalization of leadership. Londres: Routledge.

BOURDIEU, Pierre (2001). El campo político. Bolivia: Plural editores.

CHERNICK, Marc W. (1989). "Reforma política, apertura democrática y el desmonte del Frente nacional". En: Vásquez de Urrutia, Patricia (Compiladora), La democracia en blanco y negro: Colombia en los años ochenta. Colombia: Fondo Editorial CEREC.

DUGAS, John; Sánchez, Rubén y Elizabeth Ungar (1991). "La Asamblea Nacional Constituyente, expresión de una voluntad general”. En: Sánchez, Rubén (Compilador), los nuevos retos electorales. Colombia 1990: antesala del cambio. Colombia: Fondo Editorial CEREC.

GARCÍA DÍEZ, Fátima y Araceli Mateos (2006). "El 'Proyecto Elites Parlamentarias Latinoamericanas’: continuidades y cambios (1994-2005)”. En: Alcántara, Manuel (ed.), Políticos y política en América Latina. Madrid: Siglo XXI y Fundación Carolina, pp. 3-27.

KALMANOVITZ, Salomón (2010). Nueva historia económica de Colombia. Co-

20 En el original Maquiavelo dice así: "uno uomo che voglia fare in tutte le parte professione di buono, conviene rovini infra tanti che non sono buoni" (Machiavelli, 1971: 279). 
lombia: Universidad Jorge Tadeo Lozano y Editorial Taurus.

MACHIAVELLI, Niccolò (1971). "I Discorsi sopra la prima deca di Tito Livio". En: Tutte le opere, a cura di Mario Martelli. Firenze: Sansoni editore.

MARSHALL, T. H. (2007). “Ciudadanía y clase social”. En: Marshall, T. H. y Bottomore, Tom, Ciudadanía y Clases Sociales. Madrid: Alianza Editorial.

MELO, Jorge Orlando (1989). "La Constitución de 1886”. En: Nueva historia de Colombia, Vol. III. Bogotá: Editorial Planeta.

PALACIOS, Marco (2001). Entre la legitimidad y la violencia. Colombia 1875 1994. Colombia: Editorial Norma.

PIZARRO LEONGÓMEZ, Eduardo (2004). Una democracia asediada. Balance y perspectivas del conflicto armado en Colombia. Colombia: Editorial Norma.

PUTNAM, Robert (2000). Bowling Alone: The Collapse and Revival of American Community. New York: Simon and Schuster.

ROHRSCHNEIDER, Robert (1994). "Report from the laboratory: the influence of institutions on political elites' democratic values in Germany". En: American Political Science Review, December. Vol. 88, No 4.

ROIZ, Javier (2012). "Maestros y gobernantes en la vida democrática". En: Foro Interno, No. 12, pp.: 9-27. Madrid: Universidad Complutense.

SENNETT, Richard (2003). Respect: in a world of inequality. New York and London: Norton and Company.

WEBER, Max (1972). El político y el científico. Madrid: Alianza Editorial.

Documentos de prensa

EL ESPECTADOR. Edición Online. Colombia. http://www.elespectador.com/noticias/ judicial/articulo-422140-condenan-30-anos-de-prision-cesar-perez-garcia-masacre-de-segovi

EL ESPECTADOR (2008 al 2012). Colombia.

SEMANA (2008 al 2012). Colombia.

CAMBIO (2008 al 2009). Colombia. 


\section{Anexos}

\section{Tabla 5}

Ejes y variables-indicadores de análisis

\begin{tabular}{|c|c|}
\hline Ejes de análisis & Variables-indicadores \\
\hline Democracia & $\begin{array}{l}\text { - Definición de democracia } \\
\text { - Ventajas y desventajas del sistema democrático colombiano } \\
\text { - Grado de satisfacción con el sistema democrático } \\
\text { - Confianza en el sistema democrático y electoral }\end{array}$ \\
\hline $\begin{array}{l}\text { Instituciones políticas } \\
\text { y leyes }\end{array}$ & $\begin{array}{l}\text { - Definición de instituciones políticas } \\
\text { - Grado de confianza en las instituciones políticas } \\
\text { - Grado de confianza y respeto por las leyes } \\
\text { - Grado de respeto por las instituciones políticas } \\
\text { - Ideal de instituciones políticas }\end{array}$ \\
\hline Partidos políticos & $\begin{array}{l}\text { - Identificación partidista } \\
\text { - Valoración del bipartidismo } \\
\text { - Valoración de los sistemas pluripartidistas } \\
\text { - Confianza en los partidos } \\
\text { - Grado de satisfacción con la participación política en los partidos } \\
\text { - Grado de democracia en los partidos }\end{array}$ \\
\hline $\begin{array}{l}\text { Identificación } \\
\text { ideológica }\end{array}$ & $\begin{array}{l}\text { - Autoidentificación ideológica (izquierda / derecha / centro izquierda / } \\
\text { centro derecha }\end{array}$ \\
\hline Libertad e igualdad & $\begin{array}{l}\text { - Definición de igualdad y libertad } \\
\text { - Valoración de la igualdad y la libertad } \\
\text { - Grado de libertad e igualdad en la democracia colombiana }\end{array}$ \\
\hline $\begin{array}{l}\text { Poder públicos } \\
\text { (ejecutivo / legislativo / } \\
\text { judicial) }\end{array}$ & $\begin{array}{l}\text { - Grado de importancia en los poderes públicos en la democracia } \\
\text { - Grado de confianza en los poderes públicos } \\
\text { - Grado de democracia en los poderes públicos } \\
\text { - Confianza y respeto en los poderes públicos }\end{array}$ \\
\hline Fuerzas militares & $\begin{array}{l}\text { - Opinión sobre el control civil de las Fuerzas Militares } \\
\text { - Valoración sobre la actuación de la Fuerzas militares }\end{array}$ \\
\hline $\begin{array}{l}\text { Cuál es el principal } \\
\text { problema de la } \\
\text { democracia colombiana }\end{array}$ & $\begin{array}{l}\text { - Opinión sobre: pobreza, desigualdad social, clientelismo, corrupción, } \\
\text { narcotráfico, conflicto armado (guerrilla / paramilitarismo), paz, } \\
\text { desplazamiento forzado, centralización política, medio ambiente }\end{array}$ \\
\hline $\begin{array}{l}\text { Valores y características } \\
\text { sociodemográficas }\end{array}$ & $\begin{array}{l}\text { - Género, edad, profesión, religión, práctica religiosa, opinión sobre : } \\
\text { aborto, divorcio, matrimonio entre parejas del mismo sexo, eutanasia, } \\
\text { uso de la dosis mínima }\end{array}$ \\
\hline
\end{tabular}

